Pacific Journal of Mathematics

A LOWER BOUND FOR THE NUMBER OF CONJUGACY 


\title{
A LOWER BOUND FOR THE NUMBER OF CONJUGACY CLASSES IN A FINITE NILPOTENT GROUP
}

\author{
GARY SHERMAN
}

\begin{abstract}
A lower bound is given for the number of conjugacy classes in a finite nilpotent group which reflects the nilpotency class of the group.
\end{abstract}

The problem of estimating the number of conjugacy classes, $k$, in a finite group $G$, has been around since the turn of the century. Probably the earliest version of the problem is the question: Do there exist groups of arbitrarily large finite order with a fixed number of conjugacy classes? In 1903 Landau [4] answered this question in the negative by showing $k(G)$ goes to infinity with $|G|$. By refining Landau's technique, Erdos and Turan [2] proved $k(G)>$ $\log _{2} \log _{2}|G|$. The known lower bound for $k(G)$ when $G$ is nilpotent is somewhat better, $k(G)>\log _{2}|G|$. This follows from a parametric equation for $k(G)$ when $G$ is a $p$-group given by Poland [5].

In [3] Gustafson posed the problem of finding improved lower bounds for $k(G)$. Recently, Bertram [1] provided a substantial improvement of the $\log _{2} \log _{2}|G|$ bound which holds for "most" group orders. The purpose of this note is to give a lower bound for $k(G)$ when $G$ is nilpotent which reflects the nilpotency class of $G$ and improves the $\log _{2}|G|$ bound.

THEOREM. If $G$ is a finite nilpotent group of nilpotency class $n$, then $k(G) \geqq n|G|^{1 / n}-n+1$.

Proof. We observe that

$$
G=Z_{0} \cup\left(\bigcup_{i=1}^{n} Z_{i}-Z_{i-1}\right)
$$

where $e=Z_{0} \varsubsetneqq Z_{1} \subsetneq \cdots \varsubsetneqq Z_{n}=G$ is the upper central series of $G$. Since $Z_{i}$ and $Z_{i-1}$ are normal subsets of $G, Z_{i}-Z_{i-1}$ is a union of conjugacy classes of $G$. Indeed, for $x \in Z_{i}-Z_{i-1}$ and $g \in G$ we have $x^{-1} g^{-1} x g \in Z_{i-1}$ because $Z_{i} / Z_{i-1}$ is the center of $G / Z_{i-1}$. This implies $g^{-1} x g \in x Z_{i-1}$ and we conclude $\bar{x}$, the conjugacy class of $x$ in $G$, is contained in $x Z_{i-1}$. Thus $|\bar{x}| \leqq\left|x Z_{i-1}\right|=\left|Z_{i-1}\right|$ and therefore $Z_{i}-Z_{i-1}$ is a union of at least $\left|Z_{i}\right||| Z_{i-1} \mid-1$ conjugacy classes. It follows from (1) that

$$
k(G) \geqq 1+\sum_{i=1}^{n}\left(\left|Z_{i}\right| /\left|Z_{i-1}\right|-1\right)
$$




$$
\begin{aligned}
& =\left(\sum_{i=1}^{n}\left|Z_{i}\right| /\left|Z_{i-1}\right|\right)-n+1 \\
& =\frac{1}{n}\left(\sum_{i=1}^{n} n\left|Z_{i}\right| /\left|Z_{i-1}\right|\right)-n+1 .
\end{aligned}
$$

The arithmetic-geometric means inequality applied to the sum in (2) yields

$$
\begin{aligned}
k(G) & \geqq\left(\prod_{i=1}^{n} n\left|Z_{i}\right| /\left|Z_{i-1}\right|\right)^{1 / n}-n+1 \\
& =n|G|^{1 / n}-n+1 .
\end{aligned}
$$

Let us illustrate how this result can be used to sharpen the $\log _{2}|G|$ bound for $k(G)$. Specifically, suppose $G$ is a nilpotent group of order $2^{5} 5^{7} 7^{4}$. We note that $k(G) \geqq 33$ since $\log _{2}\left(2^{5} 5^{7} 7^{4}\right)>32$.

Can we determine the nilpotency class of $G$ ? Not exactly, but the class of a nilpotent group is the maximum of the classes of its $p$-Sylow subgroups and the class of a $p$-group of order $p^{m}, m \geqq 3$, is at most $m-1$ so the class of $G$ is at most 6 . Fortunately $n|G|^{1 / n}-n+1$ is a decreasing function of $n$ and therefore $k(G) \geqq$ $6\left(2^{5} 5^{7} 7^{4}\right)^{1 / 6}-5>250$. Thus $k(G) \geqq 251$. To improve this bound we make use of the fact that $k(G)$ is multiplicative; i.e., the number of conjugacy classes in a direct product is the product of the number of conjugacy classes in each factor. This implies $k(G) \geqq$ $\left(4 \cdot 2^{5 / 4}-3\right)\left(6 \cdot 5^{7 / 6}-5\right)\left(3 \cdot 7^{4 / 3}-2\right)>8510$. Thus $k(G) \geqq 8511$.

As a corollary to the theorem and the preceding remarks:

THEOREM. If $G$ is a finite nilpotent of order $p_{1}^{r_{1}} p_{2}^{r_{2}} \cdots p_{s}^{r_{s}}$ and nilpotency class $n$, then

$$
k(G) \geqq \prod_{i=1}^{s}\left(t_{i}\left(p_{i}^{r_{i} / t_{i}}\right)-t_{i}+1\right) \geqq n|G|^{1 / n}-n+1>\log _{2}|G|,
$$

where the $p_{i}$ 's are distinct primes and $t_{i}=\max \left\{1, r_{i}-1\right\}$.

\section{REFERENCES}

1. E. A. Bertram, A density theorem on the number of conjugacy classes in finite groups, Pacific J. Math., 55 (1974), 329-333.

2. P. Erdös and P. Turan, On some problems of a statistical group-theory, IV, Acta Math. Acad, Sci. Hung., 19 (1968), 413-435.

3. W. H. Gustafson, What is the probability that two group elements commute? Amer. Math. Monthly, 80 (1973), 1031-1034.

4. E. Laudau, Klassenzahl binarer quadratischer Formen von negativer Discriminante, Math. Annalen, 56 (1903), 674-678.

5. J. Poland, Two problems on finite groups with $k$ conjugacy classes, J. Austral. Math. Soc., 8 (1968), 45-55.

Received May 31, 1978.

Rose-Hulman Institute of Technology

Terre HaUte, IN 47803 


\section{PACIFIC JOURNAL OF MATHEMATICS}

\section{EDITORS}

RICHARD ARENS (Managing Editor)

University of California

Los Angeles, California 90024

C. W. CURTIS

University of Oregon

Eugene, OR 97403

C. C. MOORE

University of California

Berkeley, CA 94720
J. DugundjI

Department of Mathematics University of Southern Californı Los Angeles, California 90007

R. Finn and J. Milgram Stanford University Stanford, California 94305

ASSOCIATE EDITORS

E. F. BECKENBACH

B. H. NeUmanN

F. WOLF

K. YoSHIDA

\section{SUPPORTING INSTITUTIONS}

UNIVERSITY OF BRITISH COLUMBIA CALIFORNIA INSTITUTE OF TECHNOLOGY

UNIVERSITY OF CALIFORNIA

MONTANA STATE UNIVERSITY

UNIVERSITY OF NEVADA, RENO

NEW MEXICO STATE UNIVERSITY

OREGON STATE UNIVERSITY

UNIVERSITY OF OREGON
UNIVERSITY OF SOUTHERN CALIFORNIA

STANFORD UNIVERSITY

UNIVERSITY OF HAWAII

UNIVERSITY OF TOKYO

UNIVERSITY OF UTAH

WASHINGTON STATE UNIVERSITY

UNIVERSITY OF WASHINGTON 


\section{Pacific Journal of Mathematics}

\section{Vol. 80, No. $1 \quad$ September, 1979}

Jeroen Bruijning and Jun-iti Nagata, A characterization of covering dimension by

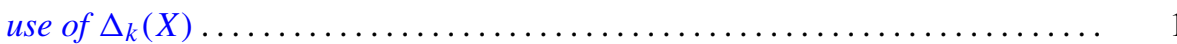

John J. Buoni and Albert Jonathan Klein, On the generalized Calkin algebra ...... 9

Thomas Ashland Chapman, Homotopy conditions which detect simple homotopy

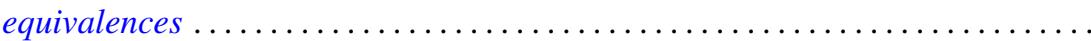

John Albert Chatfield, Solution for an integral equation with continuous interval

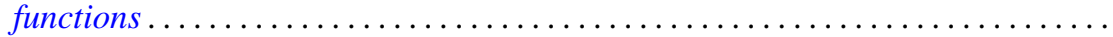

Ajit Kaur Chilana and Ajay Kumar, Spectral synthesis in Segal algebras on

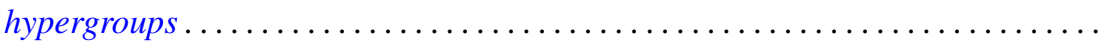

Lung O. Chung, Jiang Luh and Anthony N. Richoux, Derivations and

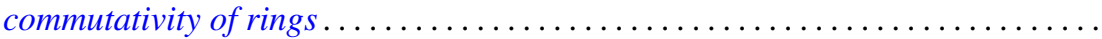

Michael George Cowling and Paul Rodway, Restrictions of certain function spaces to closed subgroups of locally compact groups .....................

David Dixon, The fundamental divisor of normal double points of surfaces........

Hans Georg Feichtinger, Colin C. Graham and Eric Howard Lakien,

Nonfactorization in commutative, weakly selfadjoint Banach algebras . . . . . . .

Michael Freedman, Cancelling 1-handles and some topological imbeddings ....... .

Frank E., III Gerth, The Iwasawa invariant $\mu$ for quadratic fields . . . . . . . . . . . . . .

Maurice Gilmore, Three-dimensional open books constructed from the identity

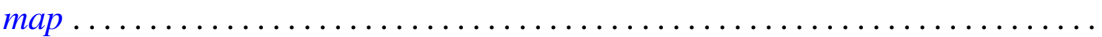

Stanley P. Gudder, A Radon-Nikodým theorem for $*$-algebras .

Peter Wamer Harley, III and George Frank McNulty, When is a point Borel? .

Charles Henry Heiberg, Fourier series with bounded convolution powers . .

Rebecca A. Herb, Characters of averaged discrete series on semisimple real Lie

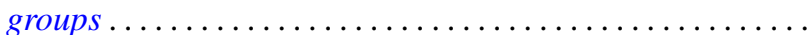

Hideo Imai, On singular indices of rotation free densities . .

Sushil Jajodia, On 2-dimensional CW-complexes with a single 2-cell . . .

Herbert Meyer Kamowitz, Compact operators of the form $u C_{\varphi}$

Matthew Liu and Billy E. Rhoades, Some properties of the Chebyshev method...

213

George Edgar Parker, Semigroups of continuous transformations and generating

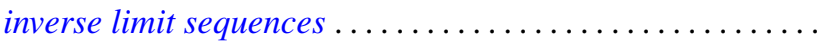

Samuel Murray Rankin, III, Oscillation results for a nonhomogeneous

equation ...

Martin Scharlemann, Transverse Whitehead triangulations ...

Gary Joseph Sherman, A lower bound for the number of conjugacy classes in a

finite nilpotent group

Richard Arthur Shoop, The Lebesgue constants for $\left(f, d_{n}\right)$-summability .

Stuart Jay Sidney, Functions which operate on the real part of a uniform

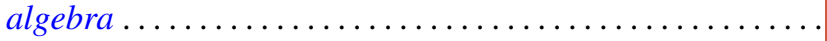

Tim Eden Traynor, The group-valued Lebesgue decomposition 